\title{
The Experiences of People with Dementia and Informal Carers Related to the Closure of Social and Medical Services in Poland during the COVID-19 Pandemic-A Qualitative Study
}

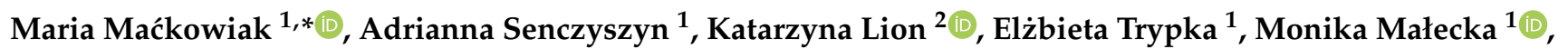 \\ Marta Ciułkowicz ${ }^{1}$, Justyna Mazurek ${ }^{3}{ }^{\mathbb{D}}$, Roksana Świderska ${ }^{4}$, Clarissa Giebel ${ }^{5,6}{ }^{\mathbb{D}}$, Mark Gabbay ${ }^{5,6}$, \\ Joanna Rymaszewska ${ }^{1}$ and Dorota Szcześniak ${ }^{1}$
}

1 Department of Psychiatry, Wroclaw Medical University, 50-367 Wroclaw, Poland; adrianna.senczyszyn@student.umw.edu.pl (A.S.); elzbieta.trypka@umw.edu.pl (E.T.); monika.malecka@student.umw.edu.pl (M.M.); marta.ciulkowicz@student.umw.edu.pl (M.C.); joanna.rymaszewska@umw.edu.pl (J.R.); dorota.szczesniak@umw.edu.pl (D.S.)

2 Menzies Health Institute Queensland, Griffith University, Brisbane, QLD 4111, Australia; k.lion@griffith.edu.au

3 University Rehabilitation Centre, Wroclaw Medical University, 50-556 Wroclaw, Poland; justyna.mazurek@umw.edu.pl

4 School of Medicine, University of Liverpool, Liverpool L69 3GE, UK; roksanaswiderska92@gmail.com

check for updates

Citation: Maćkowiak, M.;

Senczyszyn, A.; Lion, K.; Trypka, E.; Małecka, M.; Ciułkowicz, M.; Mazurek, J.; Świderska, R.; Giebel, C.; Gabbay, M.; et al. The Experiences of People with Dementia and Informal Carers Related to the Closure of Social and Medical Services in Poland during the COVID-19 Pandemic-A Qualitative Study. Healthcare 2021, 9 , 1677. https://doi.org/10.3390/ healthcare9121677

Academic Editor: Phyo Kyaw Myint

Received: 29 October 2021

Accepted: 30 November 2021

Published: 3 December 2021

Publisher's Note: MDPI stays neutral with regard to jurisdictional claims in published maps and institutional affiliations.

Copyright: () 2021 by the authors. Licensee MDPI, Basel, Switzerland. This article is an open access article distributed under the terms and conditions of the Creative Commons Attribution (CC BY) license (https:// creativecommons.org/licenses/by/ $4.0 /)$.
5 Department of Primary Care and Mental Health, University of Liverpool, Liverpool L69 3GF, UK; clarissa.giebel@liverpool.ac.uk (C.G.); mbg@liverpool.ac.uk (M.G.)

6 NIHR ARC NWC, Liverpool L69 3GL, UK

* Correspondence: maria.mackowiak@student.umw.edu.pl

\begin{abstract}
Older people with dementia are particularly at risk of COVID-19; however, relatively little is known about the indirect impact of the pandemic on the lives of those living with, and/or caring for someone with, dementia. The aim of this study was to investigate the experiences of people with dementia and informal carers during the closure of available social and medical services in Poland during the COVID-19 pandemic. A qualitative thematic analysis of semi-structured interviews with people with dementia $(n=5)$ and informal carers $(n=21)$ was performed between June and August 2020 after the first wave of COVID-19 in Poland. Three overarching themes were identified: (1) care re-organization; (2) psychological responses; (3) emerging needs. The factor underlying all these elements was reliance on other people. Social support and engagement are vital to the ongoing health and well-being of people living with dementia and their informal carers. Services need to be strengthened to provide ongoing provision to those living with dementia to reach pre-pandemic levels, if not better. Within the post-pandemic environment, people with dementia and their informal carers need reassurance that they can rely on external institutional and social support able to meet their needs.
\end{abstract}

Keywords: dementia; COVID-19; social support; medical support; people with dementia; informal carers

\section{Introduction}

As the protracted COVID-19 pandemic waxes and wanes, the needs of people living with dementia and their informal carers remain largely unaddressed and poorly understood [1-3]. These key therapeutic needs are primarily associated with daily activity, companionship and emotional support which significantly influence the quality of life of a person with dementia and influence the course of the disease [4]. Coronavirus has particularly threatened the physical health of people with dementia who might be more prone to infection, usually through older age, comorbidities or frailty [5], leading to moves to protect and isolate them from exposure which has had significant unintended adverse consequences for their dementia and emotional well-being [1,6-8]. 
Social health is usefully defined as the opportunity to fulfill one's potential through individual resources and a stimulating social environment [9-11]. It has three pillars, which are: (1) the ability of people with dementia to fulfil their potential and obligations, (2) the ability to manage life with some degree of independence despite the disease and (3) participation in meaningful social activities and interactions [12]. The pandemic restrictions and recommendations for maintaining physical distance deprived people with dementia of a stimulating social environment, the second pillar of social health. The imposed social isolation withdrew people from interpersonal contacts which, until now, were opportunities to fulfill their social roles and assisted in symptom-related constraints. The balance between the capabilities and limitations maintained by a supportive environment was decisive for overall health $[1,11,13]$.

The majority of people with dementia in Poland live within their local communities and are cared for by their families, who may live with, or be close to, them [14,15]. Until the outbreak of the pandemic, social engagement of people with dementia was provided both formally and informally. Some people with dementia could benefit from institutional support, i.e., provided by day care facilities (daily activities, cognitive stimulation and company) $[16,17]$. However, due to the insufficient institutional post-diagnostic support in Poland, a large proportion of people with dementia are not supported by formal care services, but only by their relatives $[14,18]$. Their social involvement is based on contacts with family and neighbors, and on daily activities. During the first wave of the pandemic, the available support options were suspended or significantly reduced [18,19]. Day care facilities were legally suspended [20] and contacts with relatives, in accordance with sanitary recommendations, were kept to a minimum $[6,21]$.

Emerging evidence suggests that constraints in social participation of a person with dementia and limited access to social services have affected the entire family system, particularly the primary informal carer [22,23], who is usually left alone with their caring responsibilities due to the reduction in all forms of support they previously obtained [24]. Research conducted since the outbreak of the COVID-19 pandemic [25] appears to reinforce the finding from pre-pandemic research on informal carers' burden [26]. Already a few years ago, researchers identified informal carers of people with dementia as the invisible second patients [27] who experience a high level of burden, organizational strain, psychological and physical morbidity and social isolation $[27,28]$. In the face of an ongoing pandemic, previously recognized issues seem to be escalated [25]. The frequently high levels of stress associated with caring for a person living with dementia [28] have been intensified even further by the pandemic and have negatively influenced carers' overall psychological well-being $[8,22,29]$. For informal carers who are professionally active, switching to remote work became their only means to provide their relatives with the necessary care, imposing additional caring responsibilities upon them [30]. Those with lower levels of resilience were even more liable to experience increased mental health symptoms such as anxiety and depression [31]. Although evidence highlights the negative consequences of the pandemic on the informal carer's role, for others, it has reinforced their existing isolation from the mainstream society as a consequence of their caregiving role [32,33]. For some, the pandemic, which has resulted in spending more time with their relatives, has potentially enriched their relationship [30,34]. Previous studies [29,32,35] provided insight into the impacts of pandemics on selected aspects of the psychological functioning of people with dementia and their informal carers, but few related these phenomena directly to the issue of using care services during pandemics [36,37], and the number of studies conducted in Poland was negligible [19].

The aim of this study was to investigate the experiences of people with dementia and informal carers related to the closure of available social and medical services in Poland during the COVID-19 pandemic. The evidence from this national study provides further insights into the global effects of the pandemic on those affected by dementia. 


\section{Methods}

\subsection{Study Design}

We adopted a qualitative design to investigate the experiences of people with dementia and informal carers related to the closure of available social and medical services in Poland during the COVID-19 pandemic. We chose a thematic analysis as a convenient and in-depth method for exploring individual experiences related to the actual social context [38]. Due to the limited data on the presented topic, especially in the studied area, exploration of the personal insights can reveal unforeseen issues $[38,39]$. Consequently, this has potential to generate new hypotheses and set directions for further research in the field [40].

\subsection{Recruitment Process}

Informal carers aged 18+ who were caring for a person with dementia and people with dementia (with capacity to consent and comprehend the questions stated by a psychiatrist in a clinical assessment) accessing social care and/or social support services were enrolled in the study. Social care and social support services included: day care facilities, support groups, home rehabilitation, befriending services, visiting social worker, meal delivery and home care. The participants were recruited via outpatient memory clinics and day care facilities in the city of Wroclaw, Poland (the 4th largest urban agglomeration in Poland, with an estimated population of over 64,000) [41].

\subsection{Data Collection}

Informal carers and people with dementia who were interested in taking part in the study were contacted by telephone and invited to participate in a semi-structured telephone interview, and consented if still willing once the study was fully explained to them. The interviews were conducted by psychologists and psychiatrists between June and August 2020, after the first wave of COVID-19, when pandemic restrictions in Poland were eased.

A semi-structured interview topic guide was adapted from a parallel study conducted by Giebel et al. (2020) during April 2020 [36] and was translated according to the WHO translation protocol [42], which included a forward translation, a panel of experts, back translation, pre-testing and creation of the final version [43]. This included questions about service use before and since the COVID-19 outbreak. Each interview was audio recorded, and the mean interview length was $M=18 \min (S D=6 \min 14 \mathrm{~s})$.

\subsection{Data Analysis}

Recorded interviews were transcribed into verbatim scripts by the research team members experienced in preparing materials for qualitative analyses. Prior to analysis, all transcripts were anonymized and proofread. Reviewing the transcripts for correctness was, itself, a stage of the authors' familiarization with the data. Four researchers analyzed the data-three psychologists and one psychiatry resident. The transcripts were analyzed by applying thematic analysis - both inductive and deductive [44] - with regard to the main analytical question: "What are the experiences of people with dementia and informal carers related to the closure of available social and medical services in Poland during the COVID-19 pandemic?" Analyses were conducted separately for informal carers and for people with dementia.

At the first stage, the most information-rich transcripts of interviews with informal carers and people with dementia (one from each group, with the most extensive responses of the participants) were analyzed independently by two researchers who developed initial codes (inductive analysis). In the discussion between researchers, the codes were made uniform and gathered into a codebook. Based on this jointly developed codebook, the remaining material was analyzed by one of the researchers (deductive analysis). If there was an extract of data relevant to the analytic question that did not match any of the codes classified primarily in the codebook, the new code was assigned and added to the codebook. The coding of transcripts was performed using NVivo software (QSR International, Gambit COiS Sp.z.o.o. Karków, Poland, 2020). The researchers involved in 
the analysis during the brainstorm session grouped the individual codes into the potential themes and sub-themes. Afterwards, the researchers formulated themes from the coded data with all authors, familiarized themselves with the transcripts and codes and discussed the relevance and naming of the formulated themes and sub-themes until agreement on them was reached.

The interviews, transcription and analysis were conducted in Polish. The results are reported in English. All the quotes cited were subject to back translation to ensure the correct transfer of meaning between languages.

\section{Results}

\subsection{Participant Demographics}

We conducted 26 semi-structured interviews with informal carers $(n=21)$ and people with dementia $(n=5)$. Informal carers and people with dementia were recruited separately and they were not dyads. The majority of the sample was female (17.65\%), and the majority of informal carers $(62 \%)$ were living with a person with dementia and were adult children $(71 \%)$. The mean age of people with dementia was $81(S D=6.6 ; R a=(70-87))$, with their average period of education being 13 years $(S D=1.64 ; R a=(9-12))$. Participant demographics are summarized in Table 1.

Table 1. Demographic characteristics of people with dementia and informal carers.

\begin{tabular}{|c|c|c|c|}
\hline$N(\%)$ & People with Dementia $(n=5)$ & Informal Carers $(n=21)$ & Total Sample $(n=26)$ \\
\hline \multicolumn{4}{|l|}{ Gender } \\
\hline Female & $4(80 \%)$ & $13(61.9 \%)$ & $17(65.4 \%)$ \\
\hline Male & $1(20 \%)$ & $8(38.1 \%)$ & $9(34.6 \%)$ \\
\hline \multicolumn{4}{|l|}{ Relationship with PLWD } \\
\hline Spouse & - & $6(28.6 \%)$ & - \\
\hline Adult child & - & $15(71.4 \%)$ & - \\
\hline \multicolumn{4}{|l|}{ Living with PLWD } \\
\hline Yes & - & $13(61.9 \%)$ & - \\
\hline No & - & $8(38.1 \%)$ & - \\
\hline \multicolumn{4}{|l|}{ Dementia subtype } \\
\hline Alzheimer's disease & $2(40 \%)$ & $8(38.1 \%)$ & $10(38.5 \%)$ \\
\hline Mixed dementia & $2(40 \%)$ & $6(28.6 \%)$ & $8(30.8 \%)$ \\
\hline Vascular dementia & $0(0 \%)$ & $4(19 \%)$ & $4(15.4 \%)$ \\
\hline Not specified & $1(20 \%)$ & $2(9.5 \%)$ & $3(11.5 \%)$ \\
\hline $\begin{array}{c}\text { Dementia in Parkinson's } \\
\text { disease }\end{array}$ & $0(0 \%)$ & $1(4.8 \%)$ & $1(3.8 \%)$ \\
\hline \multicolumn{4}{|l|}{ Mean (SD), [Range] } \\
\hline Age & $78(+/-6.6)(70-87)$ & $\begin{array}{l}* 81.5(+/-4.7)(75-85) \\
* * 63.1(+/-9.9)(52-80)\end{array}$ & $80.8(+/-5.14)(70-87)$ \\
\hline Years of education & $10.8(+/-1.64)(9-12)$ & $12.9(+/-2.92)(9-17)$ & $12.5(+/-2.82)(9-17)$ \\
\hline
\end{tabular}

* Age of people with dementia living with/cared for by informal carers; ${ }^{* *}$ age of informal carers.

\subsection{Qualitative Themes}

Thematic analysis resulted in three main themes with several sub-themes. Themes were common between informal carers and people with dementia: (1) care re-organization; (2) psychological response; (3) emerging needs. Arrangement of the themes and sub-themes is illustrated in Figure 1. The most representative quotes are presented in the text. More examples are available in Appendix A. 


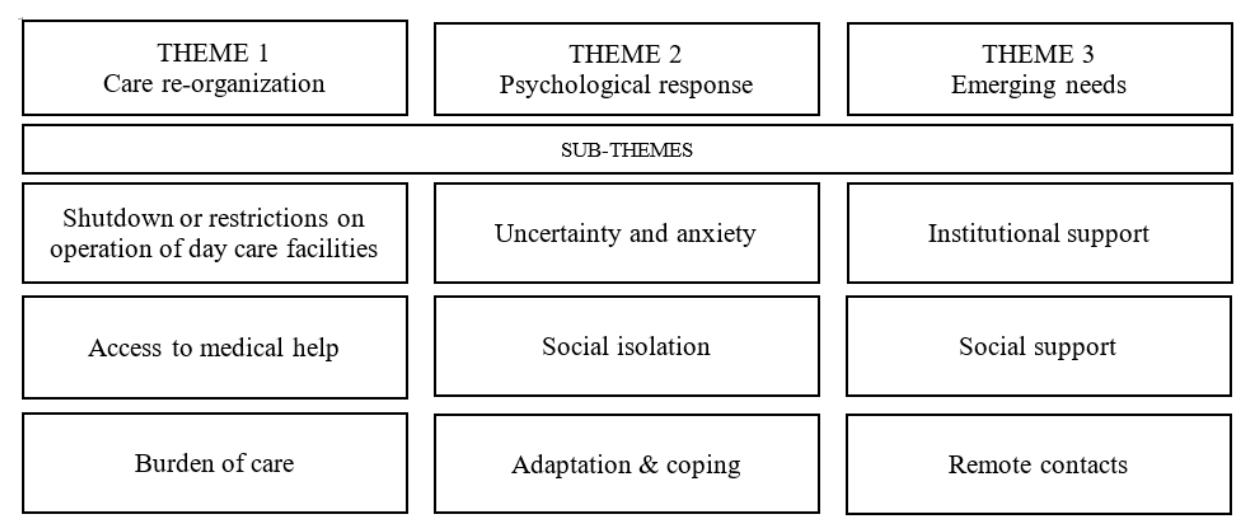

Figure 1. Themes and sub-themes.

\subsection{Theme 1: Care Re-Organization}

Restrictions imposed due to the pandemic outbreak caused significant changes in the organization of care for people with dementia. To avoid contact with potential virus carriers, people with dementia withdrew from most of their external daily activities, including attendance at day care facilities. Consequently, informal carers were tasked with providing intensified care to their relatives. The need to adapt to these changes resulted in individual psychological reactions.

\subsubsection{Shutdown or Restrictions on Operation of Day Care Facilities}

Differences in care organization during the pandemic were especially noticeable to those participants who were beneficiaries of social care facilities before. Day-to-day activities in a peer group and professional support turned out to be priceless and indispensable. Lack of a regular schedule, hours spent alone and restrictions on their own home were distressing for people with dementia and also influenced informal carers. The latter became unable to divide their care responsibilities and were worried that they would not provide enough cognitive, social and physical stimulation to their relatives.

"What I felt when they closed the day care facility? It was stress. And it still is. We had to organize something that worked well again. I didn't know when it would end, how we should work with mum, so that what was achieved in Senior Plus [daily care home] wouldn't be wasted. We share the care with our sister, but it can be difficult." [Female Informal Carer, 65, Daughter, Interview 7]

"As we were closed and not able to meet with others, it just felt like prison. It was hard to handle." [Female, Person with dementia, 82, Interview 1]

\subsubsection{Access to Medical Help}

All participants reported that COVID-19 had become a priority for the entire healthcare system, with other medical conditions sidelined. As a result, access to medical care was often challenging, especially for people with dementia and other comorbidities. Interviewees pointed to the barriers in accessing teleconsultations, which included waiting queues. Older adults highlighted the importance of a doctor's physical examination. The lack of it caused uncertainty about diagnosis and a sense of a decrease in the quality of care. Nevertheless, some participants were satisfied with telemedical solutions. This was largely dependent on the dedication of medical personnel in each facility.

"I haven't had any revolution in my life because there are telephones and I could always call for help and ask. We also have clinics here, the health care team, which is very dynamic. They are even so determined to help patients that they took us in during a pandemic when my husband's blood sugar was too high." [Female Informal Carer, 77, Wife, Interview 19]

"I wish the access to medical care was better." [Female, Person with dementia, 76, Interview 4] 


\subsubsection{Burden of Care}

Facing service closures and for fear of exposing older adults to the virus, many informal carers decided to strictly limit the number of contacts for their relatives. The duty of care usually fell on the closest person (children or a spouse) who could not count on any replacement or respite care resources. Participants underlined that it was a substantial organizational and emotional burden.

"If the carer has an institution where parents spend their time and suddenly this institution closes, then it has a negative effect on their organization of life, right?" [Female Informal Care, 58, Daughter, Interview 16]

"My daughter always said: 'Mum, you are going out-don't go out!' So as to avoid this event." [Female, Person with dementia, 70, Interview 5]

\subsection{Theme 2: Psychological Response}

Changes in the organization of everyday life and unpredictable situations initiated the process of adaptation to changed life circumstances. This process triggered different emotional reactions in informal carers and people with dementia and resulted in various attitudes and individual consequences-from difficulties in adapting to the situation to implementing positive coping strategies.

\subsubsection{Uncertainty and Anxiety}

Participants experienced many negative emotions evoked by the pandemic crisis. Fear of being infected combined with the additional caring duties or self-isolation resulted in an apparent decline in respondents' mental health. Informal carers reported increased levels of distress related mostly to their concerns about their relative with dementia. For people with dementia, pressure to stay at home increased their sense of helplessness, lack of agency and anxiety.

"It was very sad. I was lying on my bed and staring at the wall. Every day. How many people died and where? It was very sad. It lasted for so long." [Female Informal Carer, 58, Daughter in-law, Interview 10]

"Well, I got a little stressed [with the lockdown], because it is a kind of burden. If I need something, some help, there is no way to get it. If I call a doctor, it is also impossible to get to him. And it's even hard to get a prescription." [Female, Person with dementia, 76, Interview 4]

\subsubsection{Social Isolation}

Physical distancing not only impacted the organizational aspects of life but also brought on an emotional void and intensified the sense of loneliness, which particularly affected older adults. Informal carers felt powerless in the face of the adverse consequences of social isolation on their relatives. They apprehensively observed a decline in the overall functioning of people with dementia including cognitive skills, emotional well-being and physical functioning. They were concerned whether people with dementia would ever be able to return to the pre-pandemic levels of mental and physical health.

Literally, very soon after the day care facility was closed, my mother started to deteriorate in her health, especially the mental one. Her behaviours started to change, a lot of problems grew and for me it was a very big problem. I had to hire a private carer very quickly." [Female Informal Carer, 58, Daughter, Interview 1]

"I am used to being lonely. Even before that virus I lived a life of a lonely person as I had been caring for my wife for 25 years." [Male, Person with dementia, 87, Interview 2]

\subsubsection{Adaptation and Coping}

Although the COVID-19 pandemic negatively influenced many aspects of functioning, some people were able to adapt to the new circumstances. Their capacity to maintain 
a mental balance depended on the adoption of positive coping strategies, both emotion focused and problem focused. The extent to which people with dementia adjusted to the sanitary recommendations and accepted imposed requirements was notable.

"If it weren't for the optimism, we couldn't deal with such problems." [Female Carer, 75, Wife, Interview 9]

"I don't mind wearing masks if it's required." [Male, Person with dementia, 87, Interview 2]

\subsection{Theme 3: Emerging Needs}

Pandemic-related changes and the process of adjusting to the new reality revealed important needs for people with dementia and informal carers. Participants indicated what was helpful in coping with the pandemic situation, and what was missing but would be valuable.

\subsubsection{Institutional Support}

Respondents claimed that institutional support during the pandemic was insufficient and often did not meet their expectations. Help from the welfare office or personnel of day care facilities was either absent or not adequate. Most of the informal carers had to organize everything themselves. Those who received some institutional support highly appreciated it.

"Regarding the psychosocial interventions, unfortunately it was very poor. It is true that from time to time, personnel [of daily care home] sent some links to on-line exercises, but my mother cannot use it. She can't handle something like that, so it was unfortunately useless for her." [Male, Informal Carer, 58, Son, Interview 15]

\subsubsection{Social Support}

Irrespective of institutional support, participants emphasized the indispensable importance of social support. Regardless of whether it was family, friends or neighbors, any support from others prevented people with dementia and informal carers from feeling left alone. Perception of other people's willingness to help was a vital factor influencing the experience of the pandemic period, notably in reducing negative emotions.

"Of course, we are supported by friends and family. It would be hard without it. Or even hopeless." [Female Informal Carer, 77, Wife, Interview 19]

"I have had thoughts how it's going to be like and if I can handle it. But what turns out is that there are people who remember me. And they help. And this is very important for me. And that's what they tell me: if you needed help, we would help you, just tell us."

[Female, Person with dementia, 75, Interview 3]

\subsubsection{Remote Contacts}

Informal carers appreciated online forms of communication. For them, it was a useful medium of connecting with people in a time of social distancing. The Internet (social media, online support groups) allowed them to receive information about providing dementia support and reduced loneliness. However, remote forms of communication did not satisfy the needs of people with dementia. Engaging in remote communication was considered too technically challenging and did not offer emotional closeness to another person.

"It [on-line support for carers via communicators such as Zoom, Skype] is important. Because if there is no direct possibility, then you just have to look for a solution and undoubtedly some social media or some platforms that allow you to contact, (and see another person, because it is the human face that has the power), it is important. It is a form that may not be perfect, but it is good enough to be used." [Female, Informal Carer, 60, Daughter, Interview 17] 
"These teleconsultations ... well, maybe they don't quite meet my expectations. Actually, mine and my husband's. Because we have a cold, for example, we want the doctor to see us, but to auscultate the throat, to take care of the patient in such a professional way." [Female, Person with dementia, 70, Interview 5]

\section{Discussion}

This study highlights the experiences of people with dementia and informal carers related to the pandemic's public health restrictions and adds to a developing evidence base about the detrimental impacts of COVID-19 and associated restrictions on the lives of some of the most vulnerable members of society and their informal carers [36,45-48]. The results reveal various aspects of the pandemic's consequences on people's lives and changes in their care needs. They emphasize that while individuals may have individual resources, social contacts are critical for overall health and well-being in dementia.

Coronavirus restrictions suspended the functioning of the majority of care services available in Poland [49]. The results from this study show that both people with dementia and informal carers had to re-plan their care and switch to remote ways of using social and medical services. The sudden changes created a variety of psychological responses, such as emotional distress or helplessness. This started the adaptation to the critical situation [50]. The challenges posed by the pandemic additionally revealed support needs - both institutional and social — which were helpful for better adaptation to life with dementia under the pandemic regime [51].

The actual changes in the functioning of the health and social care systems reported in this study are comparable to actions taken by governments of countries struggling with the novel coronavirus around the world [52]. Prioritizing reductions in viral transmission and prioritizing care for those severely ill with COVID-19 have left dementia care needs behind. This has negatively affected the mental and social well-being of people with dementia and those who support them $[6,19,24]$.

In Poland, even before the pandemic, the dementia care system was not well organized and the major burden of care issues were left to informal carers [14,15], which is frequently the case across the globe $[28,53]$. As shown in our results, pandemic restrictions added antivirus protection tasks to daily caring duties. Despite the extra effort put into caring, they considered the support offered to not be sufficiently stimulating for people with dementia. Consequently, informal carers reported elevated physical and psychological strain. This adverse trend, according to the observations conducted thus far, has become a common experience of informal carers around the world, regardless of the care system operating in a given country $[1,19,22,35,47,54]$. Pandemic-related changes in the caring responsibilities have lowered informal carers' overall well-being, both mental and physical [33], causing symptoms such as sleep disturbances, anxiety or depression [55]. Moreover, it has increased the risk of carer burnout [47]. The intensity of these psychological reactions largely depends on intrapersonal factors such as their appraisal of the pandemic risks and consequences and their ability to adopt coping strategies [50]. Thus, the pandemic has further highlighted the need for better support infrastructure for informal carers. It is not feasible for informal carers to conduct most of the care for a person with dementia, and pandemic-related learning needs to include improved access to post-diagnostic dementia care, enabling more respite for informal carers.

Among people with dementia, we observed a burden resulting from limited interactions with the environment and feeling that one's hands are tied. Increased dependence on others with simultaneous withdrawal from the social environment disrupted the elements underlying social health [1]. Despite the preservation of personal resources such as the ability to adapt and cope with the new situation, people with dementia were deprived of the most important factors against the faster cognitive deterioration and decline in their overall well-being $[1,6,10,12]$. This situation corresponds to Talbot and Briggs' "shrinking world" theory [45] relating to the experience after receiving a dementia diagnosis [56]. COVID-19 has escalated the dominant sensation following a dementia diagnosis that the world of 
a person is narrowing. It has deprived people with dementia of the social foothold and disrupted their regular activities, posing another loss [45]. On the other hand, however, being restricted to home may have offered relief from outside sources of anxiety and could prevent people from engaging with everyday activities [57]. As a result, people with dementia were deprived of the factors helping to maintain their independence such as autonomy in dealing with everyday duties or not being treated by others in an overprotective manner [4,58-60]. Uncertainty around the coronavirus has added to the loss of the sense of control [61] and adversely affected the overall well-being of people with dementia [62-64].

Lack of environmental stimulation caused by pandemic restrictions turned out to be a considerable accelerator of decline in emotional and cognitive functioning $[36,65]$. Research suggests a wide range of specific neuropsychiatric symptoms which are mediated by this form of imposed, elongated social isolation. Among them, there are mood alterations, apathy, anxiety, reduced motor activity and appetite, circadian rhythm changes and psychotic symptoms [62,64,66-69]. In our study, it was the informal carers who reported changes in the functioning of people with dementia. They observed most of those neuropsychiatric symptoms noted elsewhere $[62,64,66,70]$ and attributed them to the imposed social isolation and closures of social services. In the face of these adverse psychological and psychiatric consequences, it is important to note that both people with dementia and informal carers are exposed to increased social isolation regardless of the pandemic restrictions $[32,47,64]$. Ongoing crises only heighten the risk of the negative effects of loneliness, thereby highlighting the importance of social support in dementia care in general $[19,62,71,72]$.

Despite the negative psychosocial consequences, our results show that people with dementia did not question the public health guidance. This is in contrast to other studies highlighting the difficulty of persuading people with dementia to comply with public safety measures $[3,51,73]$. This may be related to the characteristics of the study sample. Participants showed no behavioral disturbances and were in the early stages of dementia, which might have positively influenced their compliance due to higher levels of mental capacity and thus understanding the reasoning behind the need for public health measures [74].

The lack or inadequacy of support options reported in this study was associated with the transition to remote use of services and social contacts. In Poland, older adults, including people with dementia, are often alienated from technological progress [75], which causes difficulties in benefitting from remote support provision [6,76], including social and medical care. To date, knowledge about and usage of telemedicine in Poland have been limited [77]. Testing this solution suddenly and widely during the lockdown has highlighted barriers to its successful implementation [49]. Apart from technical difficulties, one obstacle was the general reluctance of people with dementia to engage with remote contacts. As highlighted by other studies, people with dementia experience difficulties in coping with the lack of physical contacts and suffer its consequences [6,35]. However, informal carers were more proficient in digital media use and they could benefit from the possibilities offered by technology-both organizationally and emotionally [78-80]. This is encouraging when the introduction of technological solutions to dementia care is inevitable [81,82].

Although our study provides a broad sense of the various experiences of people with dementia and informal carers, some limitations need to be considered. More carers participated than people with dementia. This may limit the picture of the pandemic situation more towards the carer perspective. Moreover, the recruitment strategy enabled us to only interview people living in Wroclaw, which is among the largest cities in Poland, thereby excluding the experiences of people with dementia and carers residing in more rural areas, who are likely to be facing additional barriers in accessing care. Bearing these limitations in mind, future research needs to explore the experiences of people with dementia and informal carers in more rural settings. A further step would be to make international comparisons in order to explore how different health and social care systems have performed in the context of providing dementia care. It should be mentioned that there are also some limitations implicitly resulting from the adopted study design. Due to 
the specificity of qualitative research, at the expense of obtaining more in-depth, individual perspectives, the representativeness of the results is limited [38,44]. The presented outcomes can therefore be treated as a source for subsequent research questions further exploring the topics from the current study. Further qualitative research can, for example, involve focus group discussion on the issues identified but insufficiently elaborated in the analyzed interviews. Such an example could be remote communication in dementia care-a topic which, although present in earlier research $[77,83]$, takes on a new meaning in the face of the COVID-19 pandemic [76,78-80]. Another issue worth exploring further in a quantitative design is coping strategies classified as a sub-theme of psychological response. A quantitative study may precisely characterize the focus of these strategies and their frequency.

\section{Conclusions}

This appears to be the first study focused on the experiences of people with dementia and informal carers related to the closure of social and medical services in Poland during the COVID-19 pandemic. The findings contribute to an emerging evidence base $[1,6,36,51,62,71]$ on the urgent needs in dementia care, highlighting the importance of social health in dementia, pointing out the malicious effects of its deprivation and emphasizing the role of social support and services both during and beyond the pandemic. Considering the inadequate state of dementia care during the pandemic, and the early consequences already noted in people with dementia and informal carers, our findings indicate an urgent requirement to fortify and extend social support and medical services to provide improved care for those affected by dementia, and their informal carers, especially in the light of the ongoing pandemic. Despite vaccinations starting to be rolled out in certain countries, another pandemic wave is accelerating, and services need to adapt flexibly and urgently to prevent further rapid deterioration among this vulnerable group. These findings are also relevant to planning to mitigate the impact of other future pandemics, not just COVID-19.

Author Contributions: Conceptualization, C.G. and D.S.; methodology, C.G., D.S. and M.M. (Maria Maćkowiak); software, M.M. (Maria Maćkowiak), A.S., M.C. and M.M. (Monika Małecka); validation, K.L. and D.S.; formal analysis, M.M. (Maria Maćkowiak), A.S., M.C. and D.S.; investigation, M.M. (Maria Maćkowiak), A.S., M.C., M.M. (Monika Małecka), R.Ś., E.T. and J.M.; resources, E.T. and M.M. (Maria Maćkowiak); data curation, M.M. (Maria Maćkowiak) and A.S.; writing—original draft preparation, M.M. (Maria Maćkowiak); writing-review and editing, C.G., M.G., D.S., K.L. and J.R.; visualization, M.M. (Maria Maćkowiak); supervision, C.G., M.G., D.S. and J.R.; project administration, C.G. and J.R.; funding acquisition, C.G. and J.R. All authors have read and agreed to the published version of the manuscript.

Funding: At the Wroclaw Medical University, the presented research results were realized within the framework of the subject with the number: SUB.C230.21.013. This is also independent research funded by the National Institute for Health Research Applied Research Collaboration North West Coast (ARC NWC). The views expressed in this publication are those of the author(s) and not necessarily those of the UK National Institute for Health Research or the UK Department of Health and Social Care.

Institutional Review Board Statement: This study was conducted according to the guidelines of the Declaration of Helsinki and approved by the Ethics Committee of Wroclaw Medical University (protocol code KB-366/220, 8 June 2020).

Informed Consent Statement: Informed consent was obtained from all subjects involved in the study.

Data availability statement: The data analyzed during this study are included in this published article and its Supplementary Information files. The full transcripts of the interviews analyzed in the study are available in Polish from the corresponding author on reasonable request.

Acknowledgments: We would like to thank all people living with dementia and informal carers who participated in this study. We acknowledge the staff of the clinical mental health clinic in Wroclaw who helped in recruiting participants.

Conflicts of Interest: The authors declare no conflict of interest. The funders had no role in the design of the study; in the collection, analyses or interpretation of data; in the writing of the manuscript, or in the decision to publish the results. 


\section{Appendix A}

Additional quotes by topic and sub-topic:

\begin{tabular}{|c|c|}
\hline & Theme 1: Care Re-Organization \\
\hline $\begin{array}{l}\text { Shutdown or restrictions } \\
\text { on operation of day } \\
\text { care facilities }\end{array}$ & $\begin{array}{l}\text { Dad used to commute [to the day care facility] himself, now he doesn't leave the house alone ... He had } \\
\text { friends, he played cards, now he doesn't ... Male Informal Carer, 55, Son, Interview } 20 \\
\text { Now we are divided into three groups, five-six people each. Our is } 6 \text { people. We are the artistic one. Generally, } \\
\text { we are isolated." Female, Person with dementia, 82, Interview } 1\end{array}$ \\
\hline Access to medical help & $\begin{array}{l}\text { I would like to be able to call the clinic, because the pharmacist said that my father was given the same drug } \\
\text { twice, under different names. I would like to consult a psychiatrist, but it is impossible, the phone is still busy } \\
\text {.. Male Informal Carer, 55, Son, Interview } 20 \\
\text { During the coronavirus pandemic access to doctors' care is extremely reduced as well as treating patients } \\
\text { with anything different from coronavirus. Female Informal Carer, } 75 \text {, Wife, Interview } 9 \\
\text { There are problems because you have to wait a long time for registration: for an appointment or a prescription. } \\
\text { You have to wait 4-5 days for a prescription. It takes four days to get a call from the doctor. So, there are } \\
\text { troubles. Female, Person with dementia, 76, Interview } 4 \\
\text { And this telemedicine ... maybe it doesn't quite meet my expectations. Actually, they are mine and my } \\
\text { husband's. For example, when we have a cold, we want the doctor to see us, we want him to listen, to examine } \\
\text { our throats, to take care of the patient. Female, Person with dementia, 70, Interview } 5\end{array}$ \\
\hline Burden of care & $\begin{array}{l}\text { When the pandemic broke out, the paid carer simply left, only me remained. I mean, the neighbours helped us } \\
\text { and someone else from the family. But at this moment everything is on me. Male Informal Carer, 80, } \\
\text { Husband, Interview } 18 \\
\text { I was very burdened, I must say, both temporally and emotionally. Because I had to think about my } \\
\text { household, to buy everything I needed, and about a household of my mother-in-law, because she did not } \\
\text { always manage. It certainly had a negative impact on me, on my psyche as a carer... somehow negatively. } \\
\text { Female Informal Carer, 60, Daughter-in-law, Interview } 6\end{array}$ \\
\hline
\end{tabular}

Theme 2: Psychological response

I felt that I would be burdened again. My sleep got worse and my GP gave me sleeping pills. Male Informal

Uncertainty and anxiety

Carer, 55, Son, Interview 12

Now there is a relapse of this coronavirus. There are many cases. And the fear of going to the store, there it is. Female, Person with dementia, 70, Interview 5

I was better, but my husband [person with dementia] felt he was locked in the house. He thought we were infected. Because of the TV news ... he interpreted it that way. Even later, when you [the psychiatrist] said not to broadcast the news over and over again. Because, unfortunately, my husband learned that if he doesn't

Social isolation come out, it means he has the coronavirus. But it must be said that the husband was emotionally disturbed that he could not go outside. He didn't want to get out of bed. He still doesn't want to. He acts as if he was sick... Female Informal Carer, 80, wife, Interview 5

Well, we were stuck indoors, we were staring at these four walls . . . Female, Person with dementia, 70, Interview 5

I don't have negative [emotions]. I just had a task: not to let senior person to contact with other people. And I did it. Female Informal Carer, 58, Daughter, Interview 14

Adaptation and coping I very rarely went outside. If I went out, I would go out into the yard. Because I had such an opportunity that I could go out to my garden and sit, you know, in a nice surrounding. Female, Person with dementia, 75, Interview 3

Theme 3: Emerging needs

It would be very valuable if there were additional care at home, for example additional exercises, so that the father-in-law would start... Because I can see that it is getting harder and harder to get him out and lead to a bus stop. He feels so tired that I just drag him out. And I have no other choice, I don't drive, my husband

Institutional support goes to work. So, I just bring him to my flat with just enough effort to keep an eye on him here. To keep him awake all the time, to exercise with him or something. A little bit of extra care at home would certainly come in handy. Informal Carer, 60 years old, daughter-in-law, Interview 6 
Sometimes it happens that I have some moments of weakness, but my sister puts me upright, sometimes I put I went to get a newspaper, something like that, but I wasn't shopping. My children were doing it for me. I didn't even cook because they brought me dinners. So, I had a luxury!" Female, Person with dementia, 82, Interview 1

[Teleconsultations] are quite difficult to put into everyday practice, as, firstly, she is not fluent in it and moreover she does not like remote options. Male Informal Carer, 57, Son, Interview 8

Remote contacts We had more time for ourselves, more time for the garden. In fact, I missed Easter the most, so we spent our time at the laptop. We also shared eggs virtually for Easter. Reunited into three families. Well, we made it! Female Informal Carer, 77, Wife, Interview 19

\section{References}

1. Vernooij-Dassen, M.; Verhey, F.; Lapid, M. The risks of social distancing for older adults: A call to balance. Int. Psychogeriatr. 2020, 32, 1235-1237. [CrossRef]

2. Alzheimer Europe Board. Alzheimer Europe Recommendations on Promoting the Wellbeing of People with Dementia and Carers during the COVID-19 Pandemic n.d. Available online: https:/ / www.alzheimer-europe.org/Policy/Our-opinion-on/2020 -Wellbeing-of-people-with-dementia-during-COVID-19-pandemic (accessed on 23 January 2021).

3. Numbers, K.; Brodaty, H. The effects of the COVID-19 pandemic on people with dementia. Nat. Rev. Neurol. 2021, 17, 69-70. [CrossRef]

4. Curnow, E.; Rush, R.; Maciver, D.; Górska, S.; Forsyth, K. Exploring the needs of people with dementia living at home reported by people with dementia and informal caregivers: A systematic review and Meta-analysis. Aging Ment. Health 2019, $25,397-407$. [CrossRef]

5. Azarpazhooh, M.R.; Amiri, A.; Morovatdar, N.; Steinwender, S.; Rezaei Ardani, A.; Yassi, N.; Biller, J.; Stranges, S.; Belasi, M.T.; Neya, S.K.; et al. Correlations between COVID-19 and burden of dementia: An ecological study and review of literature. J. Neurol. Sci. 2020, 416, 117013. [CrossRef]

6. $\quad$ Łuc, M.; Szcześniak, D.; Trypka, E.; Mazurek, J.; Rymaszewska, J. SARS-CoV-2 pandemic and the population with dementia. Recommendations under the auspices of the Polish Psychiatric Association. Psychiatr. Pol. 2020, 54, 421-436. [CrossRef]

7. Suárez-González, A.; Rajagopalan, J.; Livingston, G.; Alladi, S. The effect of COVID-19 isolation measures on the cognition and mental health of people living with dementia: A rapid systematic review of one year of quantitative evidence. EClinicalMedicine 2021, 39, 101047. [CrossRef]

8. Cohen, G.; Russo, M.J.; Campos, J.A.; Allegri, R.F. Living with dementia: Increased level of caregiver stress in times of COVID-19. Int. Psychogeriatr. 2020, 32, 1377-1381. [CrossRef]

9. Vernooij-Dassen, M.; Moniz-Cook, E.; Jeon, Y.H. Social health in dementia care: Harnessing an applied research agenda. Int. Psychogeriatr. 2018, 30, 775-778. [CrossRef]

10. De Vugt, M.; Dröes, R.M. Social health in dementia. Towards a positive dementia discourse. Aging Ment. Health 2017, 21, 1-3 [CrossRef]

11. Huber, M.; André Knottnerus, J.; Green, L.; Van Der Horst, H.; Jadad, A.R.; Kromhout, D.; Leonard, B.; Lorig, K.; Loureiro, M.I.; van der Meer, J.W.M.; et al. How should we define health? BMJ 2011, 343, d4163. [CrossRef]

12. Dröes, R.M.; Chattat, R.; Diaz, A.; Gove, D.; Graff, M.; Murphy, K.; Verbeek, H.; Vernooij-Dassen, M.; Clare, L.; Johannessen, A.; et al. Social health and dementia: A European consensus on the operationalization of the concept and directions for research and practice. Aging Ment. Health 2017, 21, 4-17. [CrossRef] [PubMed]

13. Vernooij-Dassen, M.; Moniz-Cook, E.; Verhey, F.; Chattat, R.; Woods, B.; Meiland, F.; Franco, M.; Holmerova, I.; Orrell, M.; De Vugt, M. Bridging the divide between biomedical and psychosocial approaches in dementia research: The 2019 INTERDEM manifesto. Aging Ment. Health 2021, 25, 206-212. [CrossRef] [PubMed]

14. Sadowska, A. Organizacja opieki nad chorymi na chorobe Alzheiemre w Polsce [Orgaization of care for patients with Alzheimer's disease in Poland]. In Sytuacja Osób Chorych na Chorobę Alzheimera w Polsce. Raport RPO [The Situation of People with Alzheimer's Disease in Poland. Report of the Ombudsman], 2nd ed.; Szczudlik, A., Ed.; Biuro Rzecznika Praw Obywatelskich: Warsaw, Poland, 2016; pp. 42-46.

15. Szcześniak, D.; Dröes, R.M.; Meiland, F.; Brooker, D.; Farina, E.; Chattat, R.; Evans, S.B.; Evans, S.C.; Saibene, F.L.; Urbańska, K.; et al. Does the community-based combined Meeting Center Support Programme (MCSP) make the pathway to day-care activities easier for people living with dementia? A comparison before and after implementation of MCSP in three European countries. Int. Psychogeriatr. 2018, 30, 1717-1734. [CrossRef] [PubMed]

16. Mazurek, J.; Szcześniak, D.; Lion, K.M.; Dröes, R.M.; Karczewski, M.; Rymaszewska, J. Does the meeting centres support programme reduce unmet care needs of community-dwelling older people with dementia? A controlled, 6-month follow-up Polish study. Clin. Interv. Aging 2019, 14, 113-122. [CrossRef]

17. Miranda-Castillo, C.; Woods, B.; Galboda, K.; Oomman, S.; Olojugba, C.; Orrell, M. Unmet needs, quality of life and support networks of people with dementia living at home. Health Qual. Life Outcomes 2010, 8, 113-122. [CrossRef] [PubMed] 
18. Durda, M. Organizacja opieki nad osobami z demencją w Polsce na tle krajów rozwiniętych i rozwijających się. Gerontol Pol. 2010, $18,76-85$.

19. Rusowicz, J.; Pezdek, K.; Szczepańska-Gieracha, J. Needs of alzheimer's charges' caregivers in poland in the COVID-19 pandemic-An observational study. Int. J. Env. Res. Public Health 2021, 18, 4493. [CrossRef]

20. Miejskie Centrum Usług Socjalnych we Wrocławiu, n.d. Available online: https://www.mcus.pl/projekty/projekt-moj-drugidom/aktualnosci.html (accessed on 24 September 2021).

21. Coronavirus Disease (COVID-19) Advice for the Public n.d. Available online: https:/ /www.who.int/emergencies / diseases / novel-coronavirus-2019/advice-for-public (accessed on 23 February 2021).

22. Sutcliffe, C.; Giebel, C.; Bleijlevens, M.; Lethin, C.; Stolt, M.; Saks, K.; Soto, M.E.; Meyer, G.; Zabalegui, A.; Chester, H.; et al. Caring for a Person With Dementia on the Margins of Long-Term Care: A Perspective on Burden From 8 European Countries. J. Am. Med. Dir. Assoc. 2017, 18, 967-973.e1. [CrossRef]

23. Hwang, Y.; Connell, L.S.M.; Rajpara, A.R.; Hodgson, N.A. Impact of COVID-19 on Dementia Caregivers and Factors Associated With their Anxiety Symptoms. Am. J. Alzheimer's Dis. Other Demen 2021, 36. [CrossRef]

24. Alzheimer Europe. COVID-19—Living with Dementia n.d. Available online: https://www.alzheimer-europe.org/Living-withdementia/COVID-19 (accessed on 29 January 2021).

25. Hughes, M.C.; Liu, Y.; Baumbach, A. Impact of COVID-19 on the Health and Well-being of Informal Caregivers of People with Dementia: A Rapid Systematic Review. Gerontol. Geriatr. Med. 2021, 7, 7728. [CrossRef]

26. Pinquart, M.; Sörensen, S. Spouses, Adult Children, and Children-in-Law as Caregivers of Older Adults: A Meta-Analytic Comparison. Psychol. Aging 2011, 26, 1-14. [CrossRef]

27. Brodaty, H.; Donkin, M. Family caregivers of people with dementia. Dialogues Clin. Neurosci. 2009, 11, 217-228. [CrossRef]

28. Cheng, S.T. Dementia Caregiver Burden: A Research Update and Critical Analysis. Curr. Psychiatry Rep. 2017, 19, 1-8. [CrossRef] [PubMed]

29. Keng, A.; Brown, E.E.; Rostas, A.; Rajji, T.K.; Pollock, B.G.; Mulsant, B.H.; Kumar, S. Effectively Caring for Individuals With Behavioral and Psychological Symptoms of Dementia During the COVID-19 Pandemic. Front. Psychiatry 2020, $11,573367$. [CrossRef] [PubMed]

30. Phillips, D.; Paul, G.; Fahy, M.; Dowling-Hetherington, L.; Kroll, T.; Moloney, B.; Duffy, C.; Fealy, G.; Lafferty, A. The invisible workforce during the COVID-19 pandemic: Family carers at the frontline [version 1; peer review: 2 approved]. HRB Open Res. 2020, 3, 24. [CrossRef] [PubMed]

31. Altieri, M.; Santangelo, G. The Psychological Impact of COVID-19 Pandemic and Lockdown on Caregivers of People With Dementia. Am. J. Geriatr. Psychiatry 2021, 29, 27-34. [CrossRef]

32. Aledeh, M.; Habib Adam, P. Caring for Dementia Caregivers in Times of the COVID-19 Crisis: A Systematic Review. Am. J. Nurs. Res. 2020, 8, 552-561. [CrossRef]

33. Giebel, C.; Lord, K.; Cooper, C.; Shenton, J.; Cannon, J.; Pulford, D.; Shaw, L.; Gaughan, A.; Tetlow, H.; Butchard, S.; et al. A UK survey of COVID-19 related social support closures and their effects on older people, people with dementia, and carers. Int. J. Geriatr. Psychiatry 2020, 36, 393-402. [CrossRef] [PubMed]

34. D'Cruz, M.; Banerjee, D. Caring for Persons Living With Dementia During the COVID-19 Pandemic: Advocacy Perspectives From India. Front Psychiatry 2020, 11, 603231. [CrossRef] [PubMed]

35. Wang, H.; Li, T.; Barbarino, P.; Gauthier, S.; Brodaty, H.; Molinuevo, J.L.; Xie, H.; Sun, Y.; Yu, E.; Tang, Y.; et al. Dementia care during COVID-19. Lancet 2020, 395, 1190-1191. [CrossRef]

36. Giebel, C.; Cannon, J.; Hanna, K.; Butchard, S.; Eley, R.; Gaughan, A.; Komuravelli, A.; Shenton, J.; Callaghan, S.; Tetlow, H.; et al. Impact of COVID-19 related social support service closures on people with dementia and unpaid carers: A qualitative study. Aging Ment. Health 2020, 25, 1281-1288. [CrossRef]

37. Giebel, C.; Hanna, K.; Cannon, J.; Eley, R.; Tetlow, H.; Gaughan, A.; Komuravelli, A.; Shenton, J.; Rogers, C.; Butchard, S.; et al. Decision-making for receiving paid home care for dementia in the time of COVID-19: A qualitative study. BMC Geriatr 2020, 20, 1-8. [CrossRef]

38. Braun, V.; Clarke, V. Using thematic analysis in psychology. Qual Res. Psychol. 2006, 3, 77-101. [CrossRef]

39. King, N. Using Templates in the Thematic Analysis of Text. In Essential Guide to Qualitative Methods in Organizational Research; Cassels, C., Symon, G., Eds.; Sage: London, UK, 2004; pp. 256-270. [CrossRef]

40. Morgan, D.L. From themes to hypotheses: Following up with quantitative methods. Qual. Health Res. 2015, $25,789-793$. [CrossRef] [PubMed]

41. Population Stat-World Statistical Data: Wroclaw, Poland Population n.d. Available online: https://populationstat.com/poland/ wroclaw (accessed on 23 February 2021).

42. World Health Organisation: Process of Translation and Adaptation of Instruments n.d. Available online: https://www.who.int/ substance_abuse/research_tools/translation/en/ (accessed on 23 February 2021).

43. Kalfoss, M. Translation and Adaption of Questionnaires: A Nursing Challenge. SAGE Open Nurs. 2019, 5. [CrossRef]

44. Braun, V.; Clarke, V. Successful Qualitative Research: A Practical Guide for Beginners; SAGE Publications: London, UK, 2013.

45. Talbot, C.V.; Briggs, P. "Getting back to normality seems as big of a step as going into lockdown": The Impact of the COVID-19 Pandemic on People with Early-Middle Stage Dementia. Age Ageing 2021, 50, 657-663. [CrossRef] [PubMed] 
46. Thyrian, J.R.; Kracht, F.; Nikelski, A.; Boekholt, M.; Schumacher-Schönert, F.; Rädke, A.; Michalowsky, B.; Christian, H.V.; Hoffmann, W.; Rodriguez, F.S.; et al. The Situation of Elderly with Cognitive Impairment Living at Home during Lockdown in the Corona-Pandemic in Germany. BMC Geriatr. 2020, 20, 540. [CrossRef] [PubMed]

47. Roach, P.; Zwiers, A.; Cox, E.; Fischer, K.; Charlton, A.; Josephson, C.B.; Patten, S.B.; Seitz, D.; Ismail, Z.; E Smith, E. Understanding the impact of the COVID-19 pandemic on well-being and virtual care for people living with dementia and care partners living in the community. Dementia 2020, 20, 2007-2023. [CrossRef]

48. Giebel, C.; Pulford, D.; Cooper, C.; Lord, K.; Shenton, J.; Cannon, J.; Shaw, L.; Tetlow, H.; Limbert, S.; Callaghan, S.; et al. COVID-19-related social support service closures and mental well-being in older adults and those affected by dementia: A UK longitudinal survey. BMJ Open 2021, 11, e045889. [CrossRef] [PubMed]

49. Koronawirus. Rzecznik Wskazuje MZ Najważniejsze Problemy Systemu Ochrony Zdrowia do Rozwiązania n.d. Available online: https://www.rpo.gov.pl/pl/content/koronawirus-rpo-najwazniejsze-problemy-systemu-ochrony-zdrowia (accessed on 23 February 2021).

50. Savla, J.; Roberto, K.A.; Blieszner, R.; McCann, B.R.; Hoyt, E.; Knight, A.L. Dementia caregiving during the "stay-at-home" phase of COVID-19 pandemic. J. Gerontol. Ser. B. 2020. [CrossRef] [PubMed]

51. Mok, V.C.T.; Pendlebury, S.; Wong, A.; Alladi, S.; Au, L.; Bath, P.M.; Biessels, G.J.; Chen, C.; Cordonnier, C.; Dichgans, M.; et al. Tackling challenges in care of Alzheimer's disease and other dementias amid the COVID-19 pandemic, now and in the future. Alzheimer's Dement. 2020, 16, 1571-1581. [CrossRef]

52. OECD. Beyond Containment: Health systems responses to COVID-19 in the OECD. Tackling Coronavirus Contrib a Glob Effort. Available online: https: / / read.oecd-ilibrary.org/view / ?ref=119_119689-ud5comtf84\&title=Beyond_Containment:Health_ system_responses_to_COVID-19_in_the_OECD (accessed on 23 September 2021).

53. Zwerling, J.L.; Cohen, J.A.; Verghese, J. Dementia and caregiver stress. Neurodegener Dis. Manag. 2016, 6, 69-72. [CrossRef] [PubMed]

54. Dening, K.H.; Lloyd-Williams, M. Minimising long-term effect of COVID-19 in dementia care. Lancet 2020, 396, 957-958. [CrossRef]

55. Lorenz-Dant, K.; Comas-Herrera, A. The impacts of COVID-19 on unpaid carers of adults with long-term care needs and measures to address these impacts: A rapid review of the available evidence up to November 2020. J. Long-Term Care 2021, 2021, 124-153. [CrossRef]

56. Duggan, S.; Blackman, T.; Martyr, A.; Van Schaik, P. The impact of early dementia on outdoor life: A "shrinking world"? Dementia 2008, 7, 191-204. [CrossRef]

57. Brittain, K.; Corner, L.; Robinson, L.; Bond, J. Ageing in place and technologies of place: The lived experience of people with dementia in changing social, physical and technological environments. Sociol. Health Illn. 2010, 32, 272-287. [CrossRef] [PubMed]

58. Yates, L.; Csipke, E.; Moniz-Cook, E.; Leung, P.; Walton, H.; Charlesworth, G.; Spector, A.; Hogervorst, E.; Mountain, G.; Orrell, M. The development of the promoting independence in dementia (PRIDE) intervention to enhance independence in dementia. Clin. Interv. Aging 2019, 14, 1615-1630. [CrossRef] [PubMed]

59. Von Kutzleben, M.; Schmid, W.; Halek, M.; Holle, B.; Bartholomeyczik, S. Community-dwelling persons with dementia: What do they need? What do they demand? What do they do? A systematic review on the subjective experiences of persons with dementia. Aging Ment. Health 2012, 16, 378-390. [CrossRef]

60. Schölzel-Dorenbos, C.J.M.; Meeuwsen, E.J.; Olde Rikkert, M.G.M. Integrating unmet needs into dementia health-related quality of life research and care: Introduction of the Hierarchy Model of Needs in Dementia. Aging Ment. Health 2010, 14, 113-119. [CrossRef] [PubMed]

61. Monahan, C.; Macdonald, J.; Lytle, A.; Apriceno, M.B.; Levy, S.R. COVID-19 and Ageism: How positive and negative responses impact older adults and society. Am. Psychol. 2020, 75, 887-896. [CrossRef] [PubMed]

62. Manca, R.; De Marco, M.; Venneri, A. The Impact of COVID-19 Infection and Enforced Prolonged Social Isolation on Neuropsychiatric Symptoms in Older Adults With and Without Dementia: A Review. Front. Psychiatry 2020, 11, 585540. [CrossRef]

63. Cheung, G.; Peri, K. Challenges to dementia care during COVID-19: Innovations in remote delivery of group Cognitive Stimulation Therapy. Aging Ment. Health 2020, 25, 1-3. [CrossRef] [PubMed]

64. Simonetti, A.; Pais, C.; Jones, M.; Cipriani, M.C.; Janiri, D.; Monti, L.; Landi, F.; Bernabei, R.; Liperoti, R.; Sani, G. Neuropsychiatric Symptoms in Elderly With Dementia During COVID-19 Pandemic: Definition, Treatment, and Future Directions. Front. Psychiatry 2020, 11, 579842. [CrossRef] [PubMed]

65. Hanna, K.; Giebel, C.; Tetlow, H.; Ward, K.; Shenton, J.; Cannon, J.; Komuravelli, A.; Gaughan, A.; Eley, R.; Rogers, C.; et al. Emotional and Mental Wellbeing Following COVID-19 Public Health Measures on People Living With Dementia and Carers. J. Geriatr. Psychiatry Neurol. 2021, 25. [CrossRef] [PubMed]

66. Canevelli, M.; Valletta, M.; Toccaceli Blasi, M.; Remoli, G.; Sarti, G.; Nuti, F.; Sciancalepore, F.; Ruberti, E.; Cesari, M.; Bruno, G. Facing Dementia During the COVID-19 Outbreak. J. Am. Geriatr. Soc. 2020, 68, 1673-1676. [CrossRef]

67. Gerritsen, D.L.; Voshaar, R.C.O. The effects of the COVID-19 virus on mental healthcare for older people in the Netherlands. Int. Psychogeriatr. 2020, 32, 1353-1356. [CrossRef] [PubMed]

68. Muntsant, A.; Giménez-Llort, L. Impact of Social Isolation on the Behavioral, Functional Profiles, and Hippocampal Atrophy Asymmetry in Dementia in Times of Coronavirus Pandemic (COVID-19): A Translational Neuroscience Approach. Front. Psychiatry 2020, 11, 572583. [CrossRef] [PubMed] 
69. Ziggi, I.S.; EJose, P.; Cornwell, E.Y.; Madsen, K.R.; Koushede, V.; MD, A.K.; Nielsen, L.; Koyanagi, A.; Koushede, V. Social disconnectedness, perceived isolation, and symptoms of depression and anxiety among older Americans (NSHAP): A longitudinal mediation analysis. Lancet Public Health 2020, 5, e62-e70.

70. Lara, B.; Carnes, A.; Dakterzada, F.; Benitez, I.; Piñol-Ripoll, G. Neuropsychiatric symptoms and quality of life in Spanish patients with Alzheimer's disease during the COVID-19 lockdown. Eur. J. Neurol. 2020, 27, 1744-1747. [CrossRef] [PubMed]

71. Hwang, T.J.; Rabheru, K.; Peisah, C.; Reichman, W.; Ikeda, M. Loneliness and social isolation during the COVID-19 pandemic. Int. Psychogeriatr. 2020, 32, 1217-1220. [CrossRef] [PubMed]

72. O'Shea, E. Remembering people with dementia during the COVID-19 crisis. HRB Open Res. 2020, 3, 15. [CrossRef] [PubMed]

73. Giebel, C.; Hanna, K.; Rajagopal, M.; Komuravelli, A.; Cannon, J.; Shenton, J.; Eley, R.; Gaughan, A.; Callaghan, S.; Tetlow, H.; et al. The potential dangers of not understanding COVID-19 public health restrictions in dementia: "It's a groundhog day-Every single day she does not understand why she can't go out for a walk" n.d. BMC Public Health 2021, 21, 1-9. [CrossRef]

74. Arlt, S.; Lindner, R.; Rösler, A.; Von Renteln-Kruse, W. Adherence to medication in patients with dementia: Predictors and strategies for improvement. Drugs Aging 2008, 25, 1033-1047. [CrossRef]

75. Long-Term Senior Policy in Poland for the Years 2014-2020 in Outline n.d. Available online: https:/ /das.mpips.gov.pl/source/ Long-termSeniorPolicy.pdf (accessed on 23 February 2021).

76. Arighi, A.; Fumagalli, G.G.; Carandini, T.; Pietroboni, A.M.; De Riz, M.A.; Galimberti, D.; Scarpini, E. Facing the digital divide into a dementia clinic during COVID-19 pandemic: Caregiver age matters. Neurol. Sci. 2021, 42, 1247-1251. [CrossRef] [PubMed]

77. Kańtoch, E.; Kańtoch, A. What features and functions are desired in telemedical services targeted at polish older adults delivered by wearable medical devices?-Pre-COVID-19 flashback. Sensors 2020, 20, 5181. [CrossRef] [PubMed]

78. Gabbiadini, A.; Baldissarri, C.; Durante, F.; Valtorta, R.R.; De Rosa, M.; Gallucci, M. Together Apart: The Mitigating Role of Digital Communication Technologies on Negative Affect During the COVID-19 Outbreak in Italy. Front. Psychol. 2020, 11, 554678. [CrossRef] [PubMed]

79. Canale, N.; Marino, C.; Lenzi, M.; Vieno, A.; Griffiths, M.D.; Gaboardi, M.; Girado, M.; Cervone, C.; Santinello, M. How communication technology fosters individual and social wellbeing during the COVID-19 pandemic: Preliminary support for a digital interaction model. J. Happiness Stud. 2021, 2021, 1-19. [CrossRef]

80. Garfin, D.R. Technology as a coping tool during the coronavirus disease 2019 (COVID-19) pandemic: Implications and recommendations. Stress Health 2020, 36, 555-559. [CrossRef] [PubMed]

81. Cuffaro, L.; Di Lorenzo, F.; Bonavita, S.; Tedeschi, G.; Leocani, L.; Lavorgna, L. Dementia care and COVID-19 pandemic: A necessary digital revolution. Neurol. Sci. 2020, 41, 1977-1979. [CrossRef] [PubMed]

82. Doraiswamy, S.; Abraham, A.; Mamtani, R.; Cheema, S. Use of telehealth during the COVID-19 pandemic: Scoping review. J. Med. Internet. Res. 2020, 22, e24087. [CrossRef] [PubMed]

83. Moyle, W. The promise of technology in the future of dementia care. Nat. Rev. Neurol. 2019, 15, 353-359. [CrossRef] [PubMed] 